6. Sajadieh A, Binici Z, Mouridsen MR et al. Mild hyponatremia carries a poor prognosis in community subjects. Am J Med 2009;122:679-686.

7. Waikar SS, Mount DB, Curhan GC. Mortality after hospitalization with mild, moderate, and severe hyponatremia. Am J Med 2009;122: $857-865$.

8. Heidelbaugh J, Kim A, Chang R et al. Overutilization of proton-pump inhibitors: What the clinician needs to know. Therap Adv Gastroenterol 2012;5:219-232.

9. Ozdil K, Kahraman R, Sahin A et al. Bone density in proton pump inhibitors users: A prospective study. Rheumatol Int 2013;33:2250-2260.

10. Hoorn EJ, Rivadeneira F, van Meurs JB et al. Mild hyponatremia as a risk factor for fractures: The Rotterdam Study. J Bone Miner Res 2011;26:1822-1828.

\section{AGEISM IN INTERVENTIONAL STROKE STUDIES}

To the Editor: Stroke is a disease affecting predominantly older adults; in the national stroke audits in the United Kingdom and Ireland, three-quarters of those admitted to hospital with acute stroke are aged 65 and older. ${ }^{1,2}$

Existing research is indicative of ageism in the clinical management of older adults with acute stroke. ${ }^{3}$ The data collected as part of the U.K. National Sentinel Audit of Stroke in 2004 show that older adults are less likely to be treated in a stroke unit than younger individuals $(\geq 85$ vs $<65$, risk ratio $=0.82,95 \%$ confidence interval $=0.75$ 0.90 ), and neuroimaging was performed within 24 hours of stroke in $71 \%$ of individuals younger than 65 but in $51 \%$ of those aged 85 and older.

It is undocumented as to whether ageism is also a factor in the design and implementation of interventional research studies in stroke, studies on which treatment guidelines are increasingly based. In other areas of medical research, alarming trends have been noted of the exclusion of older people from clinical trials for other conditions, leading to the paradox that a demographic group in whom medications have been least well evaluated for efficacy and side-effects are most likely to receive them. ${ }^{4}$ This ageism can manifest in at least two different forms: an arbitrary cutoff at an upper age or recruitment of samples that fail to represent the demographic profile of those affected by stroke.

It was therefore decided to review the inclusion and exclusion criteria and the mean age of participants in a U.S. government database of clinical trials in stroke.

Data were obtained from the National Institutes of Health online database of clinical trials, Clinicaltrials.gov. All closed and completed interventional stroke clinical trials up to May 2012 that had reported results for any evidence of arbitrary age cutoff in inclusion and exclusion criteria and the mean age of participants were reviewed.

The age profiles of the studies were compared with the results of the Irish National Audit of Stroke Care (INASC) from $2008^{1}$ and the U.K. National Sentinel Stroke Audit from $2010 .^{2}$

There were 110 closed interventional clinical trials with results available under the search word "stroke." After review of the trial description, only 49 studies in the database were directly related to an interventional study in stroke. Thirteen of the trials $(26.6 \%)$ had an upper age cutoff: $80(\mathrm{n}=7), 85(\mathrm{n}=4), 86(\mathrm{n}=1)$, and $95(\mathrm{n}=1)$.
The mean of the mean age of all participants in these 49 trials was $65.8 \pm 5.1$; the mean of participants in trials without an upper age cutoff $(n=36)$ was 66.9. Both of these mean ages are significantly lower than the mean age of individuals who had a stroke in Irish hospitals in INASC $(75 \pm 13)^{1}$ and the U.K. National Sentinel Stroke Audit in $2010(75.8 \pm 13.1)^{2}$

The current study confirms that the average age of participants in interventional trials is more than 10 years younger than the mean age of individuals in the population-based stroke audits performed in the United Kingdom and Ireland. Although complexity and consent challenges in the older population may in part explain this, the treatment being provided to this most vulnerable group should be based on evidence from data collected from individuals of a similar age.

One encouraging sign is the emergence of trials that focus on increasing involvement of older adults in clinical research ${ }^{4}$ including trials in stroke such as the Third International Stroke Trial, ${ }^{5}$ specifically designed to investigate the safety and efficacy for thrombolysis for ischemic stroke in individuals aged 80 and older. This demonstrates that the evaluation of medicines can become more attuned to age and more focused on older adults.

The involvement of geriatricians in stroke care may also be important in raising consciousness in attuning the age of stroke care ${ }^{6}$ and promoting greater awareness among stroke physicians, researchers, and the pharmaceutical industry of the need to mandate that the age profile of participants in trials in the testing and licensing of drugs must reflect the needs of the eventual consumer groups more accurately, and in particular older people.

\section{Adriana Hadbavna, $M B$ \\ Desmond O’Neill, MD \\ Stroke Service, Tallaght Hospital, Dublin, Ireland}

\section{ACKNOWLEDGMENTS}

Conflict of Interest: The editor in chief has reviewed the conflict of interest checklist provided by the authors and has determined that the authors have no financial or any other kind of personal conflicts with this paper.

Author Contributions: Both authors were directly involved in study concept and design, acquisition of data, analysis and interpretation of data, and preparation of manuscript.

Sponsor's Role: There was no involvement of any sponsors in this study.

\section{REFERENCES}

1. Horgan F, McGee H, Hickey A et al. From prevention to nursing home care: A comprehensive national audit of stroke care. Cerebrovasc Dis 2011;32:385-392.

2. Intercollegiate Stroke Working Party. Public Report for England, Wales and Northern Ireland. London: Royal College of Physicians, 2011.

3. Rudd AG, Hoffman A, Down C et al. Access to stroke care in England, Wales and Northern Ireland: The effect of age, gender and weekend admission. Age Ageing 2007;36:247-255.

4. Cherubini A, Oristrell J, Pla X et al. The persistent exclusion of older patients from ongoing clinical trials regarding heart failure. Arch Intern Med 2011;171:550-556. 
5. IST-3 Collaborative Group. The benefits and harms of intravenous thrombolysis with recombinant tissue plasminogen activator within $6 \mathrm{~h}$ of acute ischaemic stroke (the Third International Stroke Trial [IST-3]): A randomised controlled trial. Lancet 2012;379:2352-2363.

6. O'Neill D. 2012 - That was the year that was. Age Ageing 2013;42:140 144.

\section{SUNDOWNING SYNDROME AND HYPOTHALAMIC-PITUITARY-ADRENAL AXIS DYSREGULATION IN INDIVIDUALS WITH ALZHEIMER'S DISEASE: IS THERE AN ASSOCIATION?}

To the Editor: Sundowning syndrome (SDS) in individuals with Alzheimer's disease (AD) is a clinical phenomenon characterized by the intensification of neuropsychiatric symptoms in the late afternoon. ${ }^{1}$ This behavioral disorder is common in subjects with advanced dementia, with an incidence of $25 \%$. Despite extensive clinical literature on the features of SDS, the etiology of this neuropsychiatric manifestation remains unknown. ${ }^{2}$ Limited exposure to sunlight, disordered circadian rhythm, low levels of melatonin, sleep disturbances, and the side effects of various medications have been proposed as potential triggers of SDS, ${ }^{3}$ although there is strong evidence that $\mathrm{AD}$ is associated with irregular glucocorticoid secretion, primarily caused by dysregulation of the hypothalamic-pituitary-adrenal axis (HPA axis) and consequently likely to contribute to the behavioral disorders that individuals with $\mathrm{AD}$ exhibit. ${ }^{4,5}$ It is not clear whether the high prevalence of HPA-axis dysfunction in individuals with $\mathrm{AD}$ is associated with SDS, so the aim of this study was to investigate the potential associations between HPA axis dysregulation and SDS in individuals with Alzheimer's disease.

Fifty-one individuals with a clinically confirmed diagnosis of severe $\mathrm{AD}$ were selected from among nursing home residents of the Mons Mazzali Geriatric Institute, Mantua, Italy. An additional 24 aged-matched individuals with no symptoms of dementia or depression were selected as controls. Individuals with $\mathrm{AD}$ and controls were assessed on separate days. On Day 1, the Mini-Mental State Examination (MMSE) ${ }^{6}$ was administered, a health history was taken, a physical examination was performed, blood pressure was measured, and a blood sample was taken. To evaluate changes in neuropsychiatric symptoms throughout the day, on Days 2 and 3, a battery of neuropsychological tests was performed in the morning at 7:00 a.m. and at sunset. An increase in neuropsychiatric symptoms of more than $15 \%$ between morning and sunset was regarded as an indicator of SDS. ${ }^{1}$ The neuropsychological evaluation battery consisted of the Neuropsychiatric Inventory (NPI), ${ }^{7}$ to measure the person's behavior, and the Geriatric Depression Scale (GDS), ${ }^{8}$ to evaluate depression symptoms. Saliva samples were collected on Days 4 and 5 using collection devices (Sarstedt Salivette, Nümbrecht, Germany). Samples were collected at 7:00 a.m., 11:00 a.m., 3:00 p.m., 8:00 p.m., midnight, and sunset. Samples were centrifuged for 2 minutes at 1,000 revolutions per minute, and purified saliva was stored at $-20^{\circ} \mathrm{C}$ until it was analyzed in blind way using a cortisol assay on an immunoanalyzer system (ROCHE COBAS 6000; Roche Diagnostics, Mannheim, Germany). ${ }^{9}$ The relationship between cortisol levels and changes in neuropsychiatric

\begin{tabular}{|c|c|c|c|}
\hline Characteristic & $\begin{array}{c}\text { Controls, } \\
n=24\end{array}$ & $\begin{array}{c}\text { Participants } \\
\text { with AD } \\
\text { without SDS, } \\
n=22\end{array}$ & $\begin{array}{c}\text { Participants } \\
\text { with AD } \\
\text { and SDS, } \\
\text { n }=29\end{array}$ \\
\hline Age, mean $\pm S D$ & $86 \pm 8$ & $85 \pm 10$ & $83 \pm 9$ \\
\hline $\begin{array}{l}\text { Body mass index, } \mathrm{kg} / \mathrm{m}^{2} \text {, } \\
\text { mean } \pm \mathrm{SD}\end{array}$ & $23 \pm 4$ & $22 \pm 3$ & $23 \pm 4$ \\
\hline Sex, female/male, $n / n$ & $19 / 5$ & $18 / 4$ & $22 / 6$ \\
\hline $\begin{array}{l}\text { Systolic blood pressure, } \\
\mathrm{mmHg} \text {, mean } \pm \text { SD }\end{array}$ & $136 \pm 5$ & $135 \pm 8$ & $137 \pm 9$ \\
\hline $\begin{array}{l}\text { Diastolic blood pressure, } \\
\mathrm{mmHg} \text {, mean } \pm \mathrm{SD}\end{array}$ & $89 \pm 4$ & $88 \pm 6$ & $88 \pm 8$ \\
\hline $\begin{array}{l}\text { Glucose, } \mathrm{mg} / \mathrm{dL} \\
\text { mean } \pm \mathrm{SD}\end{array}$ & $92 \pm 4$ & $95 \pm 8$ & $96 \pm 7$ \\
\hline $\begin{array}{l}\text { Red blood cell count, } \\
10^{6} / \mu \mathrm{L} \text {, mean } \pm \mathrm{SD}\end{array}$ & $3.8 \pm 0.3$ & $4.0 \pm 0.2$ & $3.9 \pm 0.3$ \\
\hline Hemoglobin, g/dL & $12.5 \pm 1.2$ & $11.6 \pm 0.5$ & $11.2 \pm 0.8$ \\
\hline $\begin{array}{l}\text { High-density lipoprotein } \\
\text { cholesterol, } \mathrm{mg} / \mathrm{dL} \text {, } \\
\text { mean } \pm \mathrm{SD}\end{array}$ & $53 \pm 8$ & $51 \pm 9$ & $54 \pm 6$ \\
\hline $\begin{array}{l}\text { Low-density lipoprotein } \\
\text { cholesterol. ma/dL. }\end{array}$ & $109 \pm 12$ & $107 \pm 11$ & $110 \pm 14$ \\
\hline
\end{tabular}

mean \pm SD

Comorbidity, $\mathrm{n}(\%)$

Cardiovascular disease $\quad 5(21) \quad 3(14) \quad 5(17)$

Diabetes mellitus $\quad 4(17) \quad 3(14) \quad 5(17)$

$\begin{array}{llll}\text { Arthrosis } & 7(30) & 9(41) & 8(29)\end{array}$

Cataract $\quad 4(17) \quad 5(22) \quad 5(17)$

Chronic obstructive $\quad 2(8) \quad 3(14) \quad 5(17)$

pulmonary disease

Pharmacological treatments, $\mathrm{n}(\%)$

$\begin{array}{lcrr}\text { Trazodone } & 1(4) & 12(54)^{\mathrm{a}} & 14(48)^{\mathrm{a}} \\ \begin{array}{l}\text { Quetiapine fumarate } \\ \text { Promazine }\end{array} & - & 11(50)^{\mathrm{a}} & 13(45)^{\mathrm{a}} \\ \begin{array}{l}\text { hydrochloride } \\ \text { Citalopram }\end{array} & 4(16) & 8(36)^{\mathrm{a}} & 10(34)^{\mathrm{a}} \\ \text { Lorazepam } & 2(8) & 5(22)^{\mathrm{a}} & 8(29)^{\mathrm{a}} \\ \text { Salivary cortisol, nmol/L } & 2(8) & 4(18)^{\mathrm{a}} & 5(17)^{\mathrm{a}} \\ \text { 7:00 a.m. } & 12 \pm 1.0 & 13 \pm 0.9 & 17 \pm 1.1^{\mathrm{b}} \\ \text { 11:00 a.m. } & 7 \pm 1.1 & 8 \pm 0.8 & 10 \pm 0.9^{\mathrm{b}} \\ \text { 3:00 p.m. } & 4 \pm 0.5 & 4 \pm 1.1 & 7 \pm 0.8^{\mathrm{b}} \\ \text { Sunset } & 3.5 \pm 0.8 & 3.8 \pm 0.8 & 5.6 \pm 0.7^{\mathrm{b}} \\ \text { 8:00 p.m. } & 3.8 \pm 0.6 & 4 \pm 0.6 & 6 \pm 0.7^{\mathrm{b}} \\ \text { 12:00 a.m. } & 7.5 \pm 0.9 & 7.2 \pm 0.8 & 9.9 \pm 0.9^{\mathrm{b}}\end{array}$

Cognitive function, behavioral disorders, and depression (evaluated in the morning)

$\begin{array}{lrrr}\begin{array}{l}\text { Mini-Mental State } \\ \text { Examination }\end{array} & 26 \pm 3 & 12 \pm 4^{\mathrm{a}} & 13 \pm 4^{\mathrm{a}} \\ \text { NPI } & 2 \pm 1 & 20 \pm 6^{\mathrm{a}} & 19 \pm 5^{\mathrm{a}} \\ \text { GDS } & 2 \pm 2 & 6 \pm 2^{\mathrm{a}} & 6 \pm 3^{\mathrm{a}}\end{array}$

Percentage change in neuropsychiatric symptoms and depression between morning and sunset

\begin{tabular}{llll} 
NPI & $7 \pm 4$ & $9 \pm 3$ & $33 \pm 9^{\mathrm{b}}$ \\
GDS & $8 \pm 4$ & $6 \pm 4$ & $31 \pm 10^{\mathrm{b}}$ \\
\hline
\end{tabular}

${ }^{\text {a}}$ Significantly different from controls.

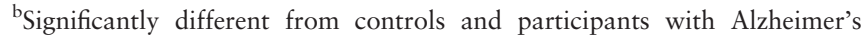
disease $(A D)$ without sundowning syndrome (SDS).

$\mathrm{SD}=$ standard deviation; NPI = Neuropsychiatric Inventory; GDS = Geriatric Depression Scale. 